\title{
Haematological Derrangement Due to $P$. falciparum Infection in Patients of Selected Health Centres in Ardo-Kola Local Government Area, Taraba State
}

\author{
Elkanah Obadiah Sambo", Obiorah Sylvester Chibuzor², Onyeuku Okechukwu Chinwe ${ }^{3, *}$, \\ Elkanah Deborah Sambo', Egeonu Stephen Ugoeze ${ }^{2}$ \\ ${ }^{1}$ Department of Biological Sciences, Taraba State University, Jalingo, Nigeria \\ ${ }^{2}$ Department of Laboratory Services, Federal Medical Centre, Jalingo, Nigeria \\ ${ }^{3}$ Department of Laboratory Services, Taraba State Specialist Hospital, Jalingo, Nigeria
}

Email address:

okechukwuonyeuku66@gmail.com (O. O. Chinwe)

${ }^{*}$ Corresponding author

\section{To cite this article:}

Elkanah Obadiah Sambo, Obiorah Sylvester Chibuzor, Onyeuku Okechukwu Chinwe, Elkanah Deborah Sambo, Egeonu Stephen Ugoeze. Haematological Derrangement Due to P. falciparum Infection in Patients of Selected Health Centres in Ardo-Kola Local Government Area, Taraba State. Biomedical Sciences. Vol. 6, No. 3, 2020, pp. 67-73. doi: 10.11648/j.bs.20200603.15

Received: July 18, 2020; Accepted: August 19, 2020; Published: September 19, 2020

\begin{abstract}
Malaria infection is one of the most common disease of public health importance afflicting millions of people in sub-Saharan Africa. This study investigated haematological derrangement among malaria infected and non-infected patients attending some Primary Health Centres in Ardo-Kola LGA, Taraba State, Nigeria. 585 blood samples were collected and examined for Plasmodium falciparum infection. Packed Cell Volume (PCV) was done by microhaematocrit and Erythrocyte Sedimentation Rate (ESR) using Westergen methods. The overall result showed a prevalence of ESR by Westergern method. It was found that malaria with low intensity of parasitaemia infection, 217 (37.09\%) was more than medium and high intensity of parasitaemia with no significant difference $\left(\chi^{2}=9.34 ; \mathrm{P} \geq 0.05\right)$. The mean value of haematological parameters of parasitized subjects were 0.29 for PCV and 124.3655 for platelets which were significantly lower than those of non-parasitized subjects, PCV $=0.4577$ and Platelets $=198.7698$ respectively. Erythrocyte Sedimentation Rate (ESR) was higher (33.0852) in parasitized subjects than non-parasitized (20.0504). The result of this study could be useful in identification of high-risk malaria population. This will target intervention and assessment of impact based on changes in haematological parameters associated with $P$. falciparum infection. Futhermore, preventive strategies like chemoprophylaxis, provision of iron supplementation and insecticide treated nets could be employed in the study area to curb the upsurge in transmission.
\end{abstract}

Keywords: Haematological, Packed, Cell, Volume, Sedimentation

\section{Introduction}

Malaria is the most important public health problem in sub-Saharan Africa. It is the cause of morbidity and mortality with more than 200 million cases and 445,000 deaths every year [1]. Malaria in humans is caused by five (5) Plasmodium parasites: Plasmodium falciparum, P. malariae, P. ovale and P. knowlesi. [1] The current distribution of human-pathogenic Plasmodium species shows preponderance of $P$. falciparum in tropical Africa, while $P$. vivax prevails over P. falciparum in South America. P. falciparum, P. Vivax and $P$. knowlesi are prevalent in south-easthern and western pacific Asia. Although P. malaria may occur in all malaria area, its prevalence is generally low. In tropical Africa, $P$. falciparum and $P$. malariae co-infection is sometimes encountered. P. Ovale is widespread principally in tropical Africa [1].

In Nigeria, there is an estimated $25 \%-30 \%$ of mortality in children under five or an estimated 300,000 deaths each year due to malaria [2].

The environment is very conducive for transmission in many parts of Nigeria and it favours malaria transmission with temperatures ranging from $20^{\circ} \mathrm{C}-28^{\circ} \mathrm{C}$ [3]. While 
malaria regularly impact the lives of Nigerians, mortality rates are especially high among pregnant women, infants under one year of age, and those of low socioeconomic status. Risk factors contributing to higher malaria associated morbidilty and mortality include: age, pregnancy, HIV/AIDS infection, migration and socioeconomic status [1].

Malaria illness is manifested in blood and involves almost all the cell lines and most prominently red blood cells, thus making it a potentially multisystem disease, as organ is reached by blood.

Despite the endemic state, there is paucity of data on the overall impact of malaria on hematological indices. Risk factors that contribute to higher malaria-associated morbidity and mortality such as age, pregnancy, migration, socioeconomic status are well established within the area under study. As a result of some of these factors, the poor nutritional state especially among the most vulnerable groups (Pregnant women, displaced persons and under-five). These affect the blood production capacity of inhabitants and thus with a super imposed malaria infection, thus only constitutes more negative health outcomes.

It is therefore imperative to understand the impact of malaria on hematological indices and how it interplays with other risk factors in the area. The study examines association between infection and certain hematological parameters such as Packed Cell Volume (PCV), Neutrophils, Erythrocyte Sedimentation Rate (ESR) among patients attending some health facilities in Ardo-Kola LGA, Taraba State.

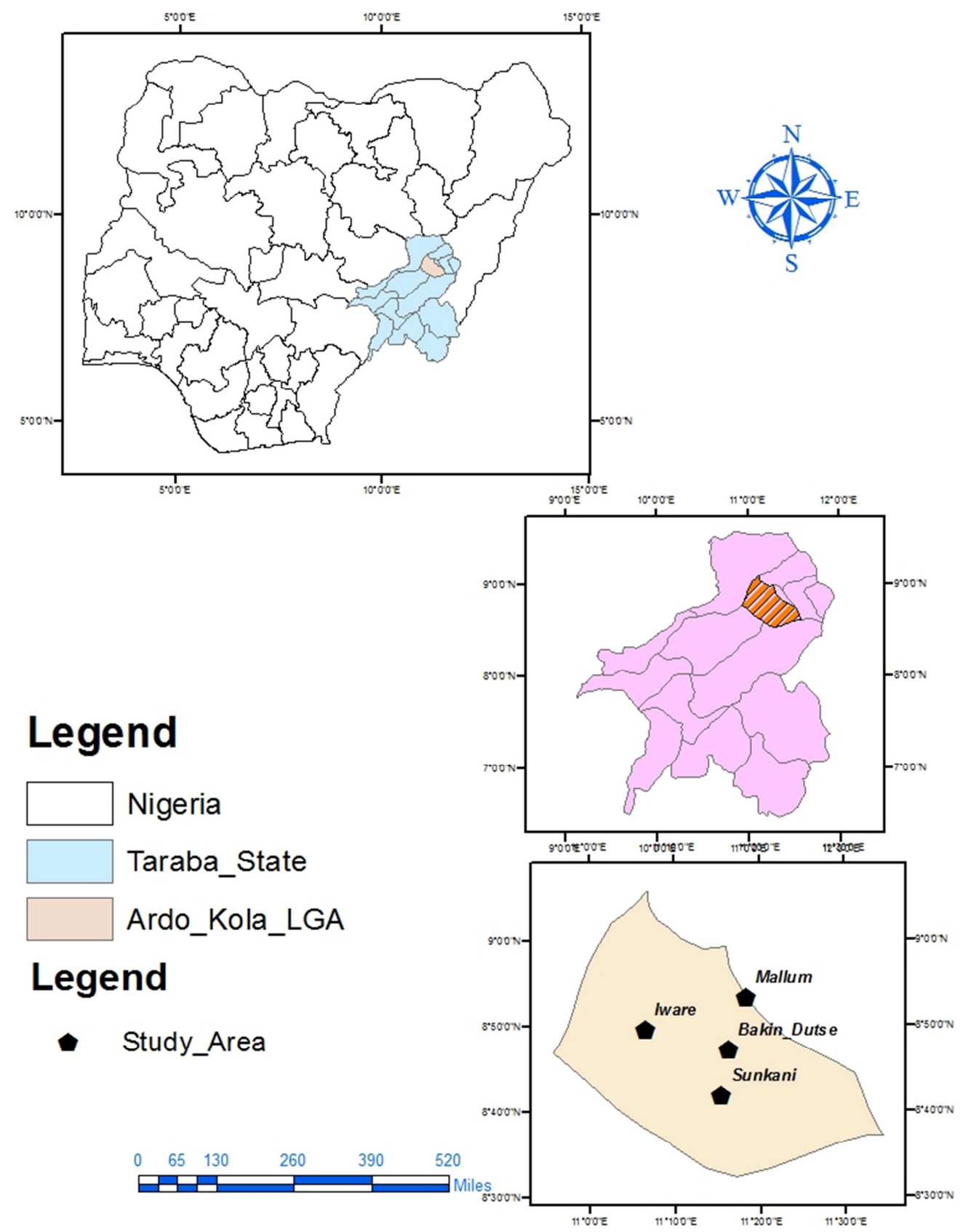

Figure 1. Map of study area, Ardo-kola Local Government Area. 


\section{Materials and Methods}

\subsection{Study Area}

Ardo-kola is a Local Government Area in Taraba State, which is in the Northeast geo-political zone of Nigeria (Figure 1). The local government area has an estimated population of 86, 921 from the 2006 National census. It has borders with Gassol and Bali LGAs in the south, Jalingo LGA in the North, Yorro LGA to the East. The districts within Ardo-kola are: Alimgora, Ardo-kola, Iware, JauroYinu, Lamido Borno, Mayo Renewo, Sarkin Dutse, Sunkani, Tau and Zangon-Kombi. The Local Government lies between longitude $9^{\circ} 17^{\prime \prime} \mathrm{N}$ and latitude $9^{\circ} 59^{\prime \prime} \mathrm{E}$ (Figure 1). The residents of the local government predominantly speak Jukun Kona, Mumuye, Fulani and Hausa languages and they are mostly farmers. The climate in the area can be described as a tropical sub-humid type with two distinct (wet and dry) seasons. It has an average rainfall of 7 months annually with total range between $1,200 \mathrm{~mm}$ and $2000 \mathrm{~mm}$ in the months of April and October. The temperature is relatively high throughout the year averaging $28^{\circ} \mathrm{C}-32^{\circ} \mathrm{C}$ with an occasional peak at $44.0^{\circ} \mathrm{C}$ between March and April.

\subsection{Study Population}

A total of 585 subjects clinically diagnosed of malaria were randomly selected from four health facilities in Ardo-kola Local Government Area of Taraba State for the study.

\subsection{Study Design and Sample Size Determination}

The research design for this study is cross sectional descriptive study.

A sample size of 585 was used based on the formula described by Fisher. The formula described by Fisher is as follows: $\mathrm{N}=\mathrm{Z}_{2} \mathrm{pq} / \mathrm{d}^{2}$, where $\mathrm{N}$ is sample size, $\mathrm{Z}=2.58$, $\mathrm{P}=$ prevalence, $\mathrm{q}=1-\mathrm{p}$ and $\mathrm{d}=0.0025$ (allowed error). The calculated population size per health centre is 140 . Then for the four (4) health centres we obtained $140 \times 4=560$, the minimum population size to be considered.

\subsection{Procedure for Data Collection}

Blood samples were collected from patients visiting primary health care facilities and other private hospitals around Ardo-kola Local Government Area, Taraba State.

Specimen from patients, regardless of their age and sex who have not received any anti-malarial drugs for the past two months with clinical presentation of malaria such as fever, headache, rigors, vomiting, diarrhoea, general malaise among subjects were used for the study.

\subsection{Ethical Permission}

Ethical permission was sought and obtained from
Postgraduate Review Committee of Biological Sciences Department. Futhermore, additional permission was sought and obtained from the Director, Primary Health Care (PHC), Department of Ardo-kola Local Government Area of Taraba State before commencement of study.

\subsection{Screening of Blood Samples}

Blood samples withdrawn from patients were collected inside sample bottles containing anticoagulant ethylene diaminetetracetic acid (EDTA). Thorough mixing of the blood with the anticogulant was done to avoid coagulation. Thin blood films were made from the blood samples, fixed with methanol and stained with $10 \%$ Giemsa stain and examined under the microscope using the oil emersion X100 objective. A rough estimate of parasitaemia was made for specimen selection. Blood samples with films showing large ring stage of $P$. falciparum parasites were processed for other hematological examinations.

\subsubsection{Preparation of Thin Blood Films}

A drop of blood was placed on a clean grease free slide, about $1 \mathrm{~cm}$ from one end, and a spreader with smooth edge was placed in front of the drop of blood inclined at angle of $45^{\circ}$ was placed in front of the drop of blood. This spreader was drown backward to make contact with the drop of blood. Afterwards, a quick forward movement was made to enable the blood spread out. The thin film was made to cover about half of the slide and to assume tongue shape. The thin film was air-dried and labelled accordingly [4].

\subsubsection{Preparation of Thick and Thin Blood Films}

Thick and thin blood films were prepared on the same slide for each subject and stained using 10\% Giemsa stain as described [4]. Using a completely clean grease free microscope slide a small drop of blood was added to the centre of the slide and a large drop about $15 \mathrm{~mm}$ to the one end of the slide. Using a smooth edge slide spreader, the thin blood film was spread immediately without delay, the large drop was spread to make a thick film to cover an area of about $15 \times 15 \mathrm{~mm}$. The slide was labelled with a 1 lead pencil, indicating date, patient name and number. The film was allowed to air dry. The thin film was fixed with absolute methanol for three minutes without touching the thick films.

\subsubsection{Counting of Parasite Numbers}

Counting of asexual parasite was carried out as described [6]. Parasitaemia was measured by counting the number of leucocytes in thick blood film, based on a putative mean count of 8000 leucocytes per $\mu$ l. The number of asexual parasites was counted against 200 leucocytes using laboratory counters (a field is always counted to the end, therefore, it is usual that the final leucocyte count will be over 200 . The parasitaemia per $\mu$ l was calculated by using the formula. 
Where, $8000=$ putative means of leucocytes.

\subsubsection{Estimation of Packed Cell Volume by Microhaematocrit Method}

Capillary tubes of $75 \mathrm{~mm}$ in Length and internal diameter of $1 \mathrm{~mm}$ were used. Each of the blood samples collected was mixed and introduced into to the tubes by capillarity, leaving at least $15 \mathrm{~mm}$ of the tube unfilled. One end of the tube was later sealed by using a plasticine sealant. Then the tube was placed in the microhaernatocrit centrifuge and was spun five minutes at a predetermined speed. Finally, the packed cell volume was read with a haematocrit reader and result recorded [5].

\subsubsection{Estimation of Total White Blood Cell Count by Bulk Dilution Method}

The estimation of total white blood cell count (WBC) was carried out as presented by Dade and Lewis [5].

Principles: The diluting fluid (Turk's solution) destroys red blood cells and platelets leaving the white blood cell intact.

\subsubsection{White Blood Cell Count Technique}

Zero point three eight $\mathrm{ml}$ of diluting fluid (Turk's solution) was dispensed into a $75 \times 10 \mathrm{~mm}$ tube. Then $0.02 \mathrm{ml}(20 \mu 1)$ of well-mixed EDTA anticoagulated venous blood was added into the $75 \times 10 \mathrm{~mm}$ tube mixed and allowed to stand for 5 minutes. A cover glass was placed into position on the improved Neubauer counting chamber until rainbow colour (Newtons rings) were seen. Then, the sample was re-mixed and using a Pasteur pipette that was held at an angle of about $45^{\circ}$. The chamber was filled with the blood sample. The chamber was left undisturbed for 1 minute to allow for the white cells to settle. The preparation was viewed using $\mathrm{x} 10$ objective and cells were counted in four large corner squares of the approved Neubauer chamber. The result was recorded in $\times 10^{9} / \mathrm{L}[5]$.

\subsubsection{Platelet Count}

In one in two hundred dilution of the blood using the diluting fluid (amonium oxalate) in a Thomapipette was prepared. The Neubauer counting chamber was charged with well mixed diluted blood and allowed to settle for 3-5 minutes. The ruled area of the counting chamber was located under $10 \mathrm{x}$ objective and the platelets were counted using a high power $(40 \mathrm{x})$ objectives in the four large corner squares $\left(4 \mathrm{~mm}^{2}\right)[5]$.

\subsubsection{Estimation of Erythrocyte Sedimentation Rate (ESR) by Westergren Method}

The estimation of erythrocyte sedimentation rate (ESR) was carried out as described [5].

Principle: When whole blood is allowed to stand for one hour in as much as the red blood cells are heavier than the suspending plasma medium, the red blood cell gradually fall leaving the clear plasma behind. The recommended tube is a straight glass tube, $300 \mathrm{~mm}$ in length and not less than 755 $\mathrm{mm}$ in diameter. A scale graduated in $\mathrm{mm}$ extends over 200 $\mathrm{mm}$. The test was performed on venous blood diluted accurately in the proportion of 1 volume of $3.8 \%$ citrate to 4 volumes of blood. Mixing of blood was done thoroughly and allowed to draw up into the Westergren tube to the $200 \mathrm{~mm}$ mark by means of a pipette. Then the tube was placed vertically on a rack and left undisturbed for 60 minutes, free from vibration and direct exposure to sunlight. At the end of 60 minutes, the ESR result was read to the nearest $1 \mathrm{~mm}$, means the height of the clear plasma above the upper limit of the column of sedimenting cells. Then, the result was recorded in $\mathrm{mm} / \mathrm{hr}$.

\subsubsection{Manual Differential White Blood Cell Count by Longitudinal Method}

This was carried out as described as follows. A drop of immersion oil was placed on a thin blood film. White blood cells were counted by examining the film using $\mathrm{x} 100$ objective and x 10 eyepiece in the microscope. A strip running the whole length of the film meant from the head to the tail was counted. If less than 100 cells were encountered in a single narrow strip, examination should be carried out the second time until a total of 100 cells were counted. All the leucocyte encountered were differentiated and classified into Neutrophils, Lymphocytes, Monocytes, Eosinophils and Basophils. The result was recorded in percentage [5].

\subsection{Statistical Analysis}

Data obtained were analyzed using Statistical Package for Social Science (SPSS) version 17.0. It was used to generate frequency distribution and percentage of parameters. Chi-square test was used to determine associations between infection and age groups and locations. Comparison were assessed using Mean $\pm \mathrm{SD}$. The level of significance was set at $\mathrm{P} \leq 0.05$.

\section{Results}

Female had a prevalence of 199 (82.23\%) than male 247 (72.01\%) of the patients examined but with no significant difference $\left(\chi^{2}=4.381 ; \mathrm{P} \geq 0.490\right)$. Female subjects with age group of 11-20 years recorded the highest prevalence of 35 $(89.74 \%)$ while the age group $41-50$ years had the least infection rate of $53(73.61 \%)$. Male subjects with age group of 21-30 years had highest prevalence of $23(88.46 \%)$ while age group 11-20 years had the lowest prevalence of 17 (45.94\%) as shown in Table 1. The statistical analysis did not show any significant difference between the age of the patients in Primary Health Care of Ardo-Kola LGA $\left(\chi^{2}=2.207 ; \mathrm{P} \geq 0.819\right)$. 
Table 1. Prevalence of P. falciparum based on gender and age groups among patients attending Ardo-Kola Primary Health Care facilities in Taraba State, Nigeria.

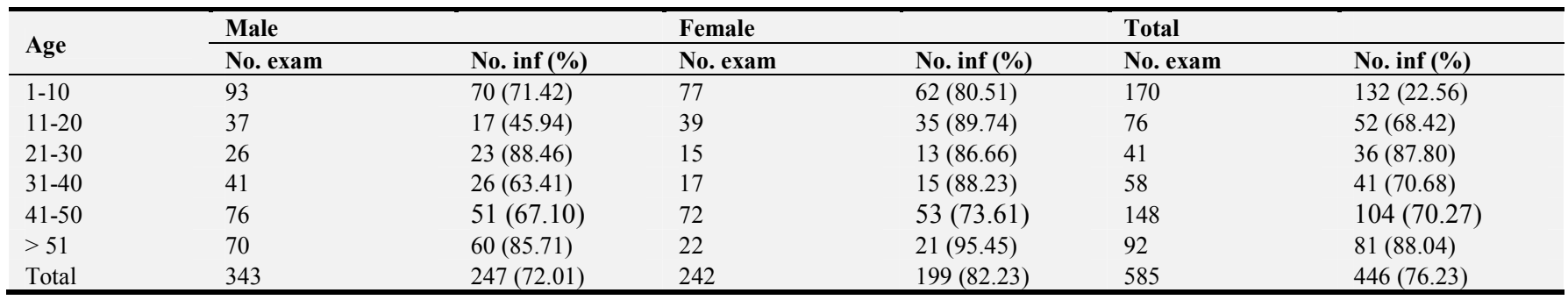

Chi-square for $P$. falciparum in $\operatorname{sex}\left(\chi^{2}=4.381 ; \mathrm{P}=0.490\right)$.

Chi-square for $P$. falciparum in age $\left(\chi^{2}=2.207 ; \mathrm{P}=0.819\right)$.

Table 2 showed the high intensity of parasitaemia $(+++)$ was found in the PHC Sunkani, 37 (19.57\%), while the medium $(++)$ and the low $(+)$ were found in PHC Iware, 32 (26.22\%) and in PHC Sunkani, 58 (30.68) respectively. The statistical analysis showed that there was no statistically significant different in the prevalence of parasitaemia load by high field in the different communities $\left(\chi^{2}=9.345 ; \mathrm{P} \geq 0.05\right)$.

Table 2. Prevalence of P. falciparum based on occupational status of patients attending Primary Health Care facilities in Ardo-Kola LGA, Taraba State, Nigeria.

\begin{tabular}{lllll}
\hline Intensity of parasitaemia (\%) & & & Medium (++) & High (+++) \\
\hline Communities & No. Examined & Low (+) & $47(24.86)$ & $37(19.57)$ \\
\hline PHC Sunkani & 189 & $58(30.68)$ & $29(19.20)$ & $16(10.59)$ \\
PHC Mallum & 151 & $62(41.05)$ & $32(26.22)$ & $19(15.57)$ \\
PHC Iware & 122 & $45(36.88)$ & $28(22.76)$ & $20(16.26)$ \\
PHC Barkin Dutse & 123 & $52(42.27)$ & $136(23.24)$ & $92(15.72)$ \\
Total & 585 & $217(37.09)$ & & \\
\hline
\end{tabular}

$\left(\chi^{2}=9.34 ; \mathrm{P} \geq 0.05\right)$.

Keys: PHC=Primary Health Care.

The mean values of haematological parameters in malaria parasitized and non-parasitized subjects are shown in Table 3 . PCV ( $\mathrm{t}=0.008, \mathrm{p} \geq 0.05)$ and monocytes $(\mathrm{t}=0.867, \mathrm{p} \geq 0.05)$ were not statistically significant between the patients examined in Ardo-Kola LGA. TWBC ( $\mathrm{t}=2.011, \mathrm{p} \leq 0.05)$, neutrophils $(\mathrm{t}=238.261, \mathrm{p} \leq 0.05)$, Lymphocytes $(\mathrm{t}=10.99$, $\mathrm{p} \leq 0.05)$, Eosinophyls $(\mathrm{t}=9.020, \mathrm{p} \leq 0.05)$, Basophils $(\mathrm{t}=41.47$, $\mathrm{p} \leq 0.05)$, Platelets $(\mathrm{t}=92.97, \mathrm{p} \leq 0.05)$ and ESR $(\mathrm{t}=30.13$, $\mathrm{p} \leq 0.05$ ) were statistically more significant among the non-parasitized patients when compared to the parasitized patients.

Table 3. Mean values of some Haematological Parameters in Malaria Parasitized and Non-parasitized Subjects among patients attending Ardo-Kola Health Care Facilities, Taraba State, Nigeria.

\begin{tabular}{|c|c|c|c|c|}
\hline Haematological Parameters & Mean value of parasitized subjects & Mean value of non-parasitized subjects & t-test & P-value \\
\hline $\mathrm{PCV}$ & 0.29 & 0.45 & 0.008 & 0.993 \\
\hline TWBC & 5.76 & 5.97 & 2.011 & 0.044 \\
\hline Neutrophils & 59.18 & 59.48 & 238.261 & 0.000 \\
\hline Eosinophils & 2.06 & 1.37 & 9.020 & 0.000 \\
\hline Monocytes & 1.32 & 1.26 & 0.867 & 0.385 \\
\hline Basophils & 0.24 & 2.71 & 41.47 & 0.000 \\
\hline ESR & 33.08 & 20.05 & 30.13 & 0.000 \\
\hline
\end{tabular}

Keys:

Normal Range of PCV.

Male: $40-50 \%$.

Female: $35-45 \%$.

Normal range of TWBC 4.00 x 10 1L-11.00 x 109 1L.

Normal Ranges for others.

Neutrophuls $40-75 \%$.

Lymphocytes $20-45 \%$.

Monocytes $2-10 \%$.

Fosinophils 1-6\%.

Basophils $<1-\%$.

Platelets $140-400$.

ESR: $0-10 \mathrm{~mm} / 1$ hour for Males and $0-20 \mathrm{~mm} / 1$ hour for Female. 
The PCV level in malaria parasitized subject within the age range of 21-30 years had the highest level of $0.38 \pm 0.39$ and within the age range of 1-10 years had the least level of $0.26 \pm 3.13$. In TWBC the highest level was $6.05 \pm 4.04$ among the age group of 11-20 years and the least level was $5.35 \pm 0.93$ among age group of 41-50 years. Also in neutrophils, age group of 1-10 years had the highest level of $62.77 \pm 10.87$ while age range of 41-50 years had the least level of 55.36 \pm 15.21 . In lymphocyte, age range of 41-50 years recorded the highest level of $40.73 \pm 16.53$ and range of $1-10$ years recorded the lowest level of $33.85 \pm 12.62$. For monocyte, it was observed that age range of 21-30 years had the level of $1.37 \pm 1.75$ and age range of $>50$ years above had the lowest level of $0.89 \pm 1.19$, while in Basophils the age group of $11-20$ years recorded the highest level of $153 \pm 2.67$ and age range of $41-50$ years recorded the lowest level of $0.00 \pm 0.00$. However, in platelet within the age range of $>51$ and above had the highest level of $127.00 \pm 41.54$, while age range within 1-10 years had the least level of $92.27 \pm 44.75$ and also in ESR age group of 21-30 years had the highest level of $33.27 \pm 31.15$ and age range of 41-50 years had the lowest level of $21.36 \pm 23.45$. Lastly Eosinophils, age group of 41-50 years recorded the highest level of $5.76 \pm 1.56$ while age range 1-10 years recorded the least level of $1.78 \pm 0.28$ (Table 3 ).

Table 4. Hematological Parameters in Malaria Parasitized Relation to Age Compared with WHO Standard Among Patients Attending Ardo-Kola Health Care Facilities.

\begin{tabular}{|c|c|c|c|c|c|c|c|c|c|}
\hline Age & PVC & TWBC & Neutrophils & Lymphocytes & Monocytes & Eosinophils & Basophils & Plateles & ESR \\
\hline $1-10$ & $0.26 \pm 3.13$ & $5.62 \pm 1.17$ & $62.77 \pm 10.87$ & $33.85 \pm 12.62$ & $1.54 \pm 1.20$ & $1.78 \pm 0.28$ & $0.02 \pm 0.14$ & $92.27 \pm 44.75$ & $27.23 \pm 24.06$ \\
\hline $11-20$ & $0.30 \pm 0.68$ & $6.05 \pm 4.04$ & $58.72 \pm 14.36$ & $36.73 \pm 15.23$ & $1.32 \pm 1.69$ & $1.80 \pm 0.23$ & $2.53 \pm 21.67$ & $120.39 \pm 48.89$ & $32.70 \pm 29.77$ \\
\hline $21-30$ & $0.30 \pm 0.39$ & $6.03 \pm 4.80$ & $60.21 \pm 14.97$ & $36.29 \pm 15.88$ & $1.37 \pm 1.75$ & $2.45 \pm 1.23$ & $0.64 \pm 8.15$ & $100.57 \pm 42.23$ & $33.27 \pm 31.15$ \\
\hline $31-40$ & $0.36 \pm 0.26$ & $5.52 \pm 0.99$ & $58.91 \pm 1.14 .74$ & $39.15 \pm 15.58$ & $1.28 \pm 1.78$ & $2.45 \pm 1.89$ & $0.0 \pm 0.09$ & $122.56 \pm 44.52$ & $27.42 \pm 30.63$ \\
\hline $41-50$ & $0.36 \pm 0.28$ & $5.35 \pm 0.93$ & $55.36 \pm 15.21$ & $40.73 \pm 16.53$ & $1.22 \pm 1.67$ & $5.76 \pm 1.56$ & $0.00 \pm 0.00$ & $121.27 \pm 40.91$ & $21.36 \pm 23.45$ \\
\hline$>51$ & $0.35 \pm .0 .07$ & $5.83 \pm 1.04$ & $59.07 \pm 17.76$ & $37.52 \pm 16.53$ & $0.89 \pm 1.19$ & $5.51 \pm 1.09$ & $0.00 \pm 0.15$ & $127.00 \pm 41.54$ & $30.73 \pm 28.73$ \\
\hline WHO Limit & $0.40-0.5$ & $4.0-11.0$ & $40.0-80.0$ & $20.0-40.0$ & $2.0-10.0$ & $1.0-6.0$ & $1.0-2.0$ & $140.0-400.0$ & $1.0-7.0$ \\
\hline
\end{tabular}

\section{Discussion}

This study showed that malaria had low intensity of infection with no significant difference among the patients. This could be the high complaint of malaria in the area. It may equally elicit hematological changes in blood. The results of the present study had shown that ESR, PCV and platelet values were out of normal ranges in malaria infections compared to the control [7]. PCV and platelet were significantly lower in the malaria patients than in the controls A lower PCV in the malaria infected patients may reflect anaemia which is often due to mechanical destruction of parasitized red cells as well as spleenic clearance of parasitized and defected erythrocytes.

A significantly lower platelets count was observed among the infected subject. Hyper-reactive splenomegaly especially in falciparum malaria, combined with humoral immune response may have contributed to the findings of lower platelet count observed in the patients in this study. This is in agreement with the report of Henry et al. [8] which stated that platelets were significantly lower in infected subjects than that of non-infected blood. The reported significant low platelet count and PCV in the patients conforms to the report who showed parasitaemia and hematological alterations in malaria [9]. The findings of this study also support the works of other researchers in different parts of Nigeria but differ with the work reported in Jos North Local Government Area of Plateau State, which reported that there was no significant variation between the hematological parameters of $P$. falciparum infected and non-infected subjects [10]. These studies from the highly affected zone showed that the infected patients tended to have significantly lower platelet counts and PCV values. Similar results were also presented by Francis et al. [11] who demonstransted low PCV and platelet in malaria patients indicating that anaemia might be involved. Haematological parameters as an investigating tool for cases of early malaria infection may help to detect early complications associated with serious malaria infections so as to help in the cure for the patients and prevent death that may result from such complications. The hematological parameters changes in malaria infected blood sample have been reported $[12,13]$. The study also revealed that the infected patients tend to have significantly lower platelet, PCV and high FSR, which is in agreement with the present study where platelet counts and PCV where significantly lower in infected than the non-infected subjects. The mean values of hematological parameters between the malaria infected and non-infected patients revealed that these parameters should be considered in malaria infection as infected subjects had lower values than those of controls. The ESR of infected subjects was significantly higher than those of the controls. The result obtained in this study is in line with previous reports $[14,15]$ of Brewerton and James [14].

\section{Conclusion}

Hematological investigation is relatively inexpensive and a less technically sophisticated way for malaria detection. Hemotological parameters of malaria infected patients in this study significantly differ from those of healthy uninfected individuals and the mean values of hematological parameters of malaria infected subjects are significantly different from the non-infected individuals. Packed Cell Volume and platelets count are lower in the infected subjects than in the non-infected. The ESR is higher in infected subjects than in 
non-infected. The present study has demonstrated that the haematological parameters are reliable and competent measures for the diagnosis of severity of malaria infections, even at the early stage.

\section{References}

[1] WHO. World Malaria Report. Geneva, Switzerland: World Health Organization, 2017. Pp 32-42.

[2] Smith, C., Teng, F. B. E., Chu, S., Joseph, K. S. Maternal and Perinatal Morbidity and Mortality Associated With Anemia in Pregnancy. Obstetrics \& Gynecology, 2019; 134 (6): 1234-1244. doi: 10.1097/AOG.0000000000003557.

[3] Edelu, B. O., Ndu, I. K., Igbokwe, O. O., Iloh, O. N. Severe falciparum malaria in children in Enugu, South East Nigeria. Nigerian Journal of Clinical Practice, 2018; 21: 1349-55.

[4] Cheesbrough, M. District laboratory practice in tropical countries. New York-Cambridge Press. Part1, $2^{\text {nd }}$ Edition, $2012 ; 249-258$.

[5] Dade, J. V. and Lewis, S. M. Practical hematology, 2001, $9^{\text {th }}$ edition. London: Churchill Livingstone.

[6] Plewes, K., Turner, G. D. H., Dondorp, A. M. Pathophysiology, clinical presentation, and treatment of coma and acute kidney injury complicating falciparum malaria, Current Opinion in Infectious Diseases, 2018; 31 (1): 69-77. doi: 10.1097/QCO.0000000000000419.

[7] WHO. World Malaria Report, 2015. Pp 543. ISBN 978-924-156-515-8.

[8] Henry, N. B., Sermé, S. S., Siciliano, G. et al Biology of Plasmodium falciparum gametocyte sex ratio and implications in malaria parasite transmission. Malar J 18, 70 (2019). https://doi.org/10.1186/s12936-019-2707-0
[9] Bakhubaira, S. "Haematological parameters in severe complicated Plasmodium falciparum malaria in adult in Aden," Turkish Journal of Haematology, 2013; 30 (40): 394-399.

[10] Draper, S. J., Sack, B. K., King, C. R. et al. Malaria Vaccines: Recent Advances and New Horizons. Cell Host Microbe. 2018; 24 (1): 43-56. doi: 10.1016/j.chom.2018.06.008.

[11] Francis, U., Isaac, Z., Yakubu, A., Enosakhare, A., Felix, E. Haematological Parameters of Malaria Infected Patients in the University of Calabar Teaching Hospital, Calabar, Nigeria. Journal of Hematology \& Thromboembolic Diseases, 2014; 2: 171. doi: 10.4172/2329-8790.1000171.

[12] Omarine, N. N., Nange, T. B. Assessment of Hematological Parameters in Malaria, among Adult Patients Attending the Bamenda Regional Hospital. Anemia, 2020: 3814513. doi: $10.1155 / 2020 / 3814513$.

[13] Mohamed, A. S., Bushra, S. A., Ahmed, M., Ali, A. E. Parasitaemia and Its Relation to Hematological Parameters and Liver Function among Patients Malaria in Abs, Hajjah, Northwest Yemen. Interdisciplinary Perspectives on Infectious Diseases, 2016. Article ID 5954394, 5 pages http://dx.doi.org/10.1155/2016/5954394.

[14] Chikezie, P. C, Okpara, R. T. Haematologic and biochemical indices of Plasmodium falciparum infected inhabitants of Owerri, Imo State, Nigeria. Journal of Medical Laboratory and Diagnosis, 4 (3): 38-44. DOI: 10.5897/JMLD2013.0068.

[15] Alves-Junior, E. R., Gomes, L. T., Dombroski, T. C., Dallabona, N., Andréia, F., Vandresen-Filho, S., Nakazato, L., Fontes, Cor J. F., Rios-Santos, F. New laboratory perspectives for evaluation of vivax malaria infected patients: a useful tool for infection monitoring. Brazilian Journal of Infectious Diseases, $\quad 2020 ; \quad 24 \quad$ (2): $120-129$. https://dx.doi.org/10.1016/j.bjid.2020.04.001. 